\title{
Adsorption of Remazol Brillant Green 6B (RBG 6B) on chitin: Process optimization using response surface methodology
}

\author{
Tepe 0.* \\ Department of Environmental Engineering, Faculty of Engineering, Firat University, 23119, Elazig, Turkey \\ Received: 01/11/2017, Accepted: 31/01/2018, Available online: 17/05/2018 \\ *to whom all correspondence should be addressed: e-mail: otepe@firat.edu.tr
}

\begin{abstract}
In the present study, the adsorption of Remazol Brillant Green 6B (RBG 6B) on chitin which characterized by BET, FTIR, XRD and SEM analysis was studied. Response surface methodology (RSM) was applied to determine interaction between solution $\mathrm{pH}$, initial RBG $6 \mathrm{~B}$ concentration and chitin dosage being individual variables and to optimize operating conditions. According to results of variance analysis (ANOVA), the second order polynomial model was statistically significant $(P<0.0001)$ and coefficient of determination value $\left(R^{2}=0.98\right)$ was high. It was determined that dye removal efficiency increased when low solution $\mathrm{pH}$ and initial RBG 6B dye concentration and high chitin dosage were used. The maximum dye removal efficiency was obtained as $88 \%$ at solution pH of 3.0 , initial RBG $6 B$ concentration of $75 \mathrm{mg} \mathrm{L}^{-1}$ and chitin dosage of $5.0 \mathrm{~g} \mathrm{~L}^{-1}$. The isotherms and kinetics studies showed that Freundlich isotherm and pseudo-second-order kinetics model fitted well to the RBG 6B adsorption data.
\end{abstract}

Keywords: Adsorption; characterization of chitin; optimization; removal; response surface methodology; RBG 6B.

\section{Introduction}

Many pollutants such as dyes, heavy metals and organic compounds are poured into water (Haldorai et al., 2015). Since dyes are consumed in many industries such as textiles, paper, dye manufacturing and dyeing industries, tanneries and food processing industries, colored wastewater in large quantities occurred (Akkaya et al., 2007; Pavlović et al., 2014; Dasgupta et al., 2016; Tehrani and Zare-Dorabei, 2016). Phthalocyanine (PC) dyes compose the basis type of the reactive dyes used in textile. They are metallic complexes used to produce blue and green shades (Matthews et al., 2009; Silva et al., 2012). Remazol Brilliant Green 6B (RBG 6B) is one of phthalocyanine dyes. Dyes in aquatic environment can create several toxic effects to the aquatic living by disturbing the food chain organisms and leading to ecological instability (Akkaya et al., 2007; Pavlović et al., 2014; Dasgupta et al., 2016). Furthermore, dyes are environmentally persistent and inhibit the photosynthesis of aquatic flora by reducing light penetration (Dasgupta et al., 2016). Because of the detrimental effects of many dyes, removal of them from wastewater is very important (Sohrabi et al., 2016). Treatment of wastewaters containing dye is so hard due to their recalcitrant structures, resistant to aerobic digestion, and stability to oxidation material (Dotto et al., 2012). Many technologies including adsorption, coagulation/flocculation, advanced oxidation processes, ozonation, membrane filtration and biological treatment for the removal of dye contaminants from wastewater have been developed and these technologies are already used (Akkaya et al., 2007; Dotto et al., 2012; Ghaedi et al., 2016). However, most of these technologies suffer from several limitations such as generally ineffective in color removal, high operational costs, less adaptable to a wide range of dye wastewaters and secondary sludge disposal problem (Dotto et al., 2012; Dursun et al., 2013; Ghaedi et al., 2016), and cannot completely remove the color from wastewater (Dursun et al., 2013). One of the perfect technologies in the removal of dyes from wastewater is adsorption in terms of energetic and environmental points of view such as high efficiency, simple operation and easy recycle and reusing of the adsorbent (Agarwal et al., 2016; Ghaedi et al., 2016). Various adsorbents such as activated carbon, polymeric materials, several agricultural wastes like sawdust, rice husk and biosorbents, nanocomposites, graphite oxide, zeolites and metal-organic materials have been reported for dye removal in the literature (Tehrani and Zare-Dorabei, 2016). Commercially available activated carbons are usually derived from natural materials such as wood or coal which is considered expensive. Hence, alternative adsorbents with an equivalent potential of activated carbon are the current thrust area of research (Subramaniam and Ponnusamy, 2015). Consequently, lowcost adsorbents are being investigated for a long time. In recent years, chitin has been used to remove dye from wastewater as alternative to expensive adsorbent. Chitin is a low-cost material obtained from natural sources such as different crustaceans, mollusks, algae, insects, fungi, and yeasts (Tang et al., 2012; Dotto et al., 2012; Labidi et al., 2016). The efficient adsorption potential of chitin can be dedicated to high hydrophilicity and high chemical reactivity because a lot of functional groups (Tang et al., 2012). 
During the recent years, it has been reported different statistical designs for optimizing of dye removal. The response Surface Methodology (RSM) can be applied in the adsorption studies and is interesting approach. RSM is a collection of mathematical and statistical techniques that use to develop, improve and optimize processes and can be used for evaluation significance of several factors. The primary aim of response surface methodology is determination of the optimum operational conditions for the system or specification a region ensuring the operating conditions (Ravikumar et al., 2005). The application of statistical experimental design techniques in process development can improve product efficiency, reduce process instability, closer confirmation of the output response to nominal and target requirements and reduce development time and overall costs (Elibol, 2004). In this study, chitin was used for removing of RBG 6B from aqueous solution. RBB $6 B$ was selected as a model dye material due to the extended use in textile industry and potential harmful effect to the environment. The main purposes of this study were threefold: firstly characterization of chitin by using several techniques such as Scanning Electron Microscopy (SEM), X-Ray Diffraction (XRD) analysis, BET surface analysis and Fourier Transform Infrared Spectroscopy (FTIR), secondly investigation of the effects of solution $\mathrm{pH}$, the initial RBG 6B concentration and chitin dosage on RBG 6B removal by chitin and thirdly optimization using response surface methodology (RSM) for bringing a new perspective to the wastewater treatment strategies. This study reported, for the first time, the feasibility of chitin as low-cost alternative adsorbent for RBG $6 B$ dye removal from aqueous solution and optimization of RBG 6B dye removal using RSM. In addition, adsorption isotherms and kinetics were also evaluated and discussed. Due to reasons mentioned above, the present study may shed light for researcher.

\section{Materials and methods}

\subsection{Materials}

Remazol Brillant Green 6B (Synonyms;Diamira Brilliant Green 6B, Helaktyn Green 6B, Reactive Blue 38) used in this experimental study was obtained from a Textile Factory in Malatya, Turkey. Molecular structure of RBG 6B is shown Fig. 1.

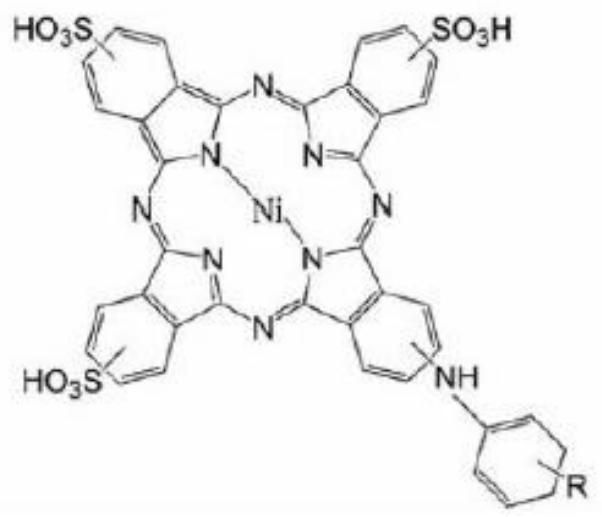

Chitin (crushed crab shells) was purchased from Sigma Chemicals Co. It was sieved to allocate the material into different particle size ranges. 297-841 $\mu \mathrm{m}$ particle sizes were selected for adsorption experiments. Distilled water was used for preparation of all solutions. Dye solutions were prepared by diluting stock solution of $1.0 \mathrm{~g} \mathrm{~L}^{-1}$. The $\mathrm{pH}$ of each solution was adjusted with diluted or concentrated $\mathrm{H}_{2} \mathrm{SO}_{4}$ and $\mathrm{NaOH}$ solutions (Thermo Scientific Orion Star A111).

\subsection{Adsorption studies}

The adsorption experiments were conducted in $250 \mathrm{~mL}$ glass flasks in an orbital shaker at $25^{\circ} \mathrm{C}$. The flasks were filled with $100 \mathrm{~mL}$ of dye solution at desired $\mathrm{pH}$ and concentration. The required amount of chitin was added and the flasks were placed on a shaker with $160 \mathrm{rpm}$ of the agitation speed. Then, the samples were collected at desired time intervals. UV/vis spectrophotometer (Perkin Elmer Lambda 25 UV-Vis Spectrophotometer) was used for analysing the dye concentration in the solution at the maximum absorption wavelength $(\lambda=620 \mathrm{~nm})$. Experiments were conducted in accordance with the central composite design (CCD) matrix shown in Table 1. The response was expressed as \% dye removal. The adsorption equilibrium was reached after $6 \mathrm{~h}$. The amounts of dye adsorbed at equilibrium $q_{e}\left(\mathrm{mg} \mathrm{g}^{-1}\right)(6 \mathrm{~h})$ and dye removal efficiency (\%) were determined using equations shown in Eqs.(1) and (2), respectively.

$$
q_{e}=\frac{\left(C_{0}-C_{e}\right) V}{m}
$$

Removal efficiency $(\%)=\left(\frac{\left(C_{0}-C_{e}\right)}{C_{0}}\right) \times 100$

Where $C_{o}$ is the initial dye concentration in solution ( $\left.\mathrm{mg} \mathrm{L}^{-1}\right), C_{e}$ is the dye concentration at the equilibrium in solution ( $\left.\mathrm{mg} \mathrm{L}^{-1}\right), m$ is the weight of adsorbent $(\mathrm{g})$, and $V$ is the volume of dye solution (L).

\subsection{Design of experimental using RSM}

Among various classification of RSM, Central Composite Design (CCD) was used to evaluate the connection between dye removal efficiency $(R \%)$ and solution $\mathrm{pH}$, initial RBG 6B concentration and chitin dosage and optimize the convenient conditions of solution $\mathrm{pH}$, initial RBG $6 \mathrm{~B}$ concentration and chitin dosage to estimate the highest removal efficiency. While $\mathrm{pH}$ of solution $(A)$, initial RBG 6B concentration $(B)$ and adsorbent dosage $(C)$ were selected as independent variables, dye removal efficiency (\%) was chosen as response. Independent variables, experimental range and level for RBG 6B removal are presented in Table 1. Each independent variable was varied over five levels between $-\alpha$ and $+\alpha$. A central composite design with six replicates at center point was employed by a total of 20 experiments. The results obtained were analyzed via StatEase Software (Design-Expert Software Version 7.0-StatEase, Inc.).

Figure 1. Molecular structure of RBG 6B dye 
Table 1. The variables and their levels for the central composite experimental design

\begin{tabular}{cccccc}
\hline Independent variables & \multicolumn{5}{c}{ Range and levels } \\
\cline { 2 - 5 } & $-1.682(-\alpha)$ & -1 & 0 & 1 & $+1.682(+\alpha)$ \\
\hline $\mathrm{pH}(A)$ & 1.3 & 3.00 & 5.5 & 8.0 & 9.7 \\
RBG 6B con. $\left(\mathrm{mg} \mathrm{L}^{-1}\right)(B)$ & 32.4 & 75 & 138 & 200 & 242.61 \\
Chitin dosage $\left(\mathrm{g} \mathrm{L}^{-1}\right)(C)$ & 0.98 & 2.0 & 3.5 & 5.0 & 6.02 \\
\hline
\end{tabular}

\subsection{Characterization}

BET surface area measurement was performed using Autosorb IQ2. The infrared spectra of chitin were registered in an ATI Unicam Mattson 1000 FTIR spectrometer. The samples were prepared in $\mathrm{KBr}$ pellets at a concentration of $1 \%(w / w)$. The X-ray diffractograms of the chitin were obtained by X-Ray Diffractometer (XRD) (PANalytical's Empyrean XRD) with radiation Cu-Ka (45 kV and $40 \mathrm{~mA}$ ) at $298-K$. The relative intensity was registered in a dispersion range $(2 \theta)$ of $5-80^{\circ}$. The structure of the chitin was investigated using a JEOL JSM $7001 \mathrm{~F}$ field emission scanning electron microscope (SEM). The composition of the chitin was characterized by EDX.

\section{Results and discussion}

\subsection{Characterization of chitin}

The surface area of the chitin was determined to be 6.667 $\mathrm{m}^{2} \mathrm{~g}^{-1}$ by BET surface area analyses. FTIR analysis can identify functional groups existing on the adsorbent surface. Since functional group has a unique energy absorption band, the functional group and their corresponding wave number can be identified (Iqbal et al.,
2016). The FTIR spectra of the chitin before and after the adsorption of dye are given in Fig. 2. Before the adsorption of RBG 6B, the peaks observed at $3423 \mathrm{~cm}^{-1}, 3140 \mathrm{~cm}^{-1}$ and $1613 \mathrm{~cm}^{-1}$ correspond to the $\mathrm{O}-\mathrm{H}$ stretching vibration, the $\mathrm{N}-\mathrm{H}$ stretching vibration, and the $\mathrm{N}-\mathrm{H}$ bending vibration, respectively. Moreover, the peaks observed at $2927 \mathrm{~cm}^{-1}$ and $1384 \mathrm{~cm}^{-1}$ were assigned to the $\mathrm{C}-\mathrm{H}$ stretching and the $\mathrm{C}-\mathrm{H}$ bending vibrations, respectively. The peaks that indicate the $\mathrm{C}-\mathrm{O}$ stretching vibration were observed at $1268 \mathrm{~cm}^{-1}$ and $1112 \mathrm{~cm}^{-1}$. Similar peaks were recorded in other studies (Rumengan et al., 2014; Dhananasekaran et al., 2016; Erdogan and Kaya, 2016). After the adsorption of RBG 6B, the shifting of some peaks was observed. The peak at $3423 \mathrm{~cm}^{-1}$ was slightly shifted to be $3440 \mathrm{~cm}^{-1}$ and the peak at $3410 \mathrm{~cm}^{-1}$ disappeared. The band intensity at $1384 \mathrm{~cm}^{-1}$ diminished. Furthermore, the peaks at $2927 \mathrm{~cm}^{-1}, 1613 \mathrm{~cm}^{-1}, 1268 \mathrm{~cm}^{-1}$ and $1112 \mathrm{~cm}^{-1}$ were slightly shifted to be $2928 \mathrm{~cm}^{-1}, 1625 \mathrm{~cm}^{-1}, 1269 \mathrm{~cm}^{-1}$ and $1115 \mathrm{~cm}^{-1}$, respectively. Similar shifting phenomenon was reported with the adsorption of dyes by chitin in the literature (Dolphen and Thiravetyan, 2011). Tang et al., (2012) considered that this can be an evident for the interaction between chitin and malachite green.

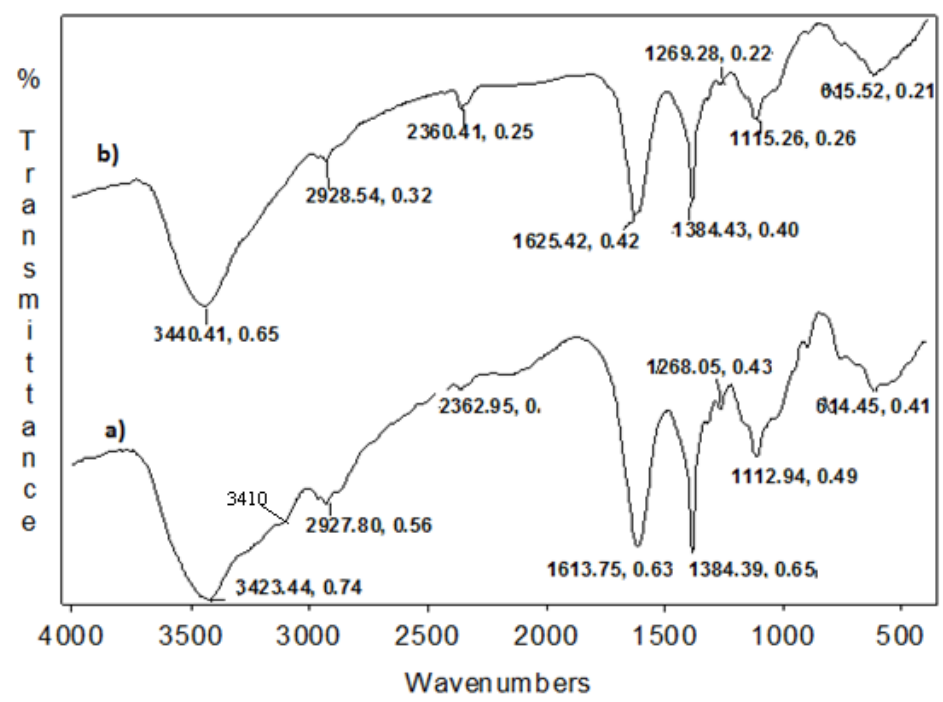

Figure 2. FTIR spectra of chitin before (a) after adsorption (b)

In order to demonstrate the crystalline structure of the chitin from crab shell, X-Ray Diffraction analysis was carried out. The diffraction pattern of chitin showed six crystalline reflections, which include two sharp and four weak peaks, in the $5-80^{\circ} 2 \theta$ range (Fig. 3). These weak peaks were around $12.72^{\circ}, 26.30^{\circ}, 34.84^{\circ}$ and $39.09^{\circ} 2 \theta$ for the chitin.
Highly intensified peaks of the chitin have $9.32^{\circ} 2 \theta$ and $d-$ spacing $9.479 \AA$ and $19.28^{\circ} 2 \theta$ and d-spacing $4.6 \AA$. The diffraction pattern of chitin used in this study has displayed similar crystalline reflections with previous studies (Shankara et al., 2015; Dhananasekaran et al., 2016; Erdogan and Kaya, 2016). 


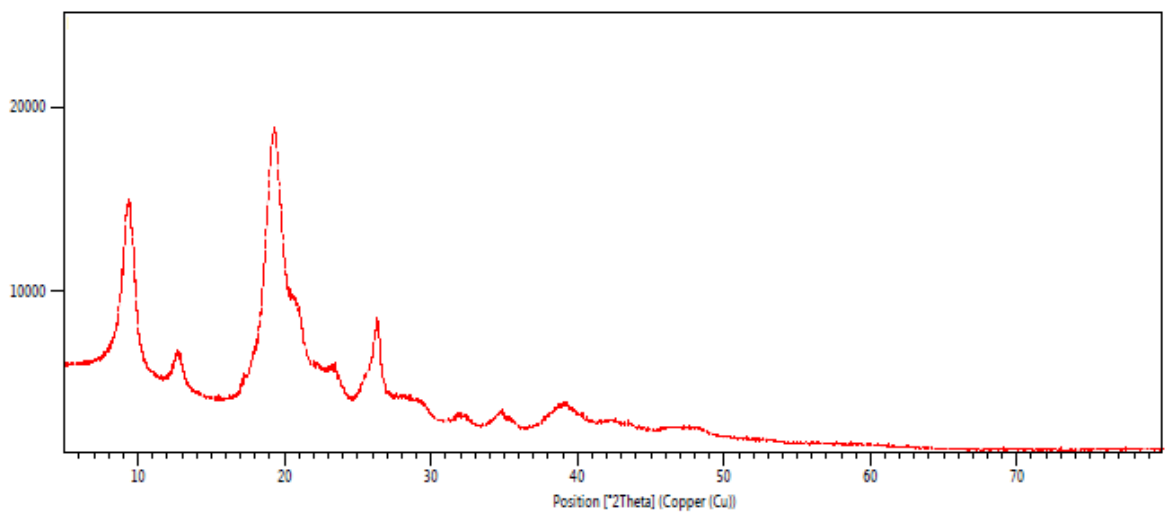

Figure 3. X-Ray diffraction pattern of chitin

The electron micrographs of chitin and chitin dyed by RBG $6 \mathrm{~B}$ are shown in Fig. $4(\mathrm{a}-\mathrm{b})$. It is observed that chitin has heterogeneous surface, fiber character and pores on surface. The fibers are long and tightly arranged. The pores are randomly distributed throughout surface. In addition, after chitin adsorbed RBG 6B on surface it has still heterogeneous surface. As reported in the literature,

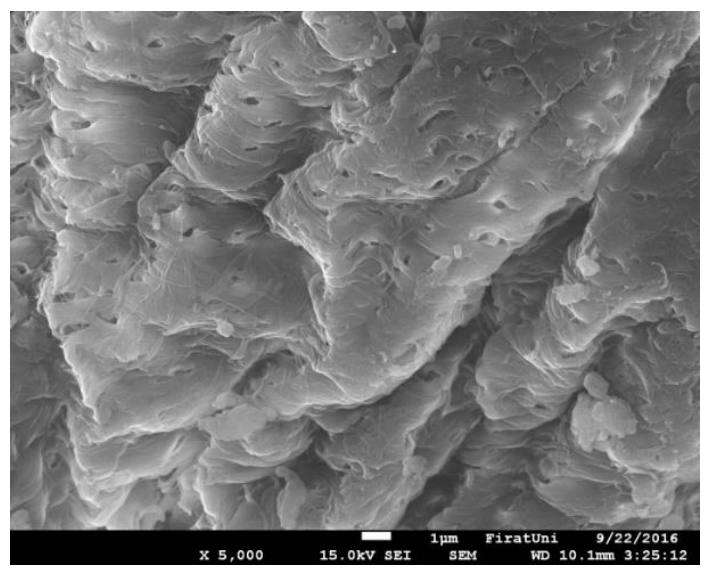

(a)

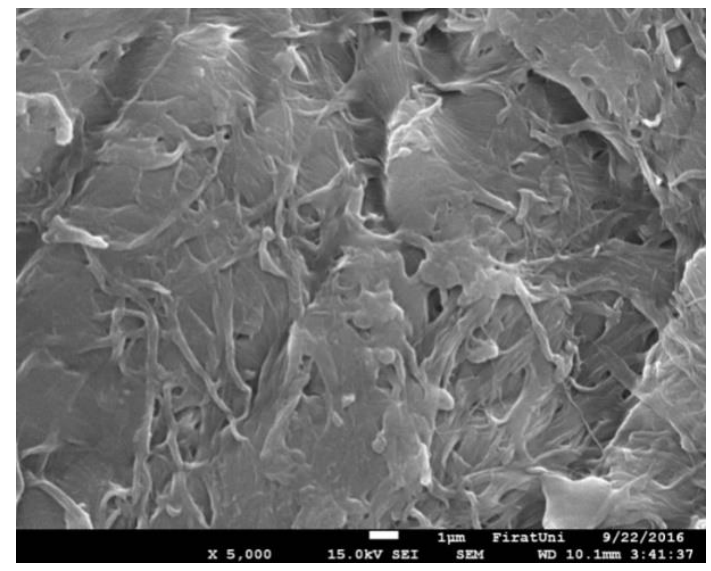

chitins gained from several organisms exhibit similar surface morphologies (Cárdenas et al., 2004; Erdogan and Kaya, 2016; Kaya et al., 2016; Waśko et al., 2016). As seen in Fig $4(a-b)$, the elemental analysis of the chitin is shown that $\mathrm{C}, \mathrm{N}$ and $\mathrm{O}$ are main constituents of the chitin, and after dyed by RBG 6B, C percentage of chitin increased.
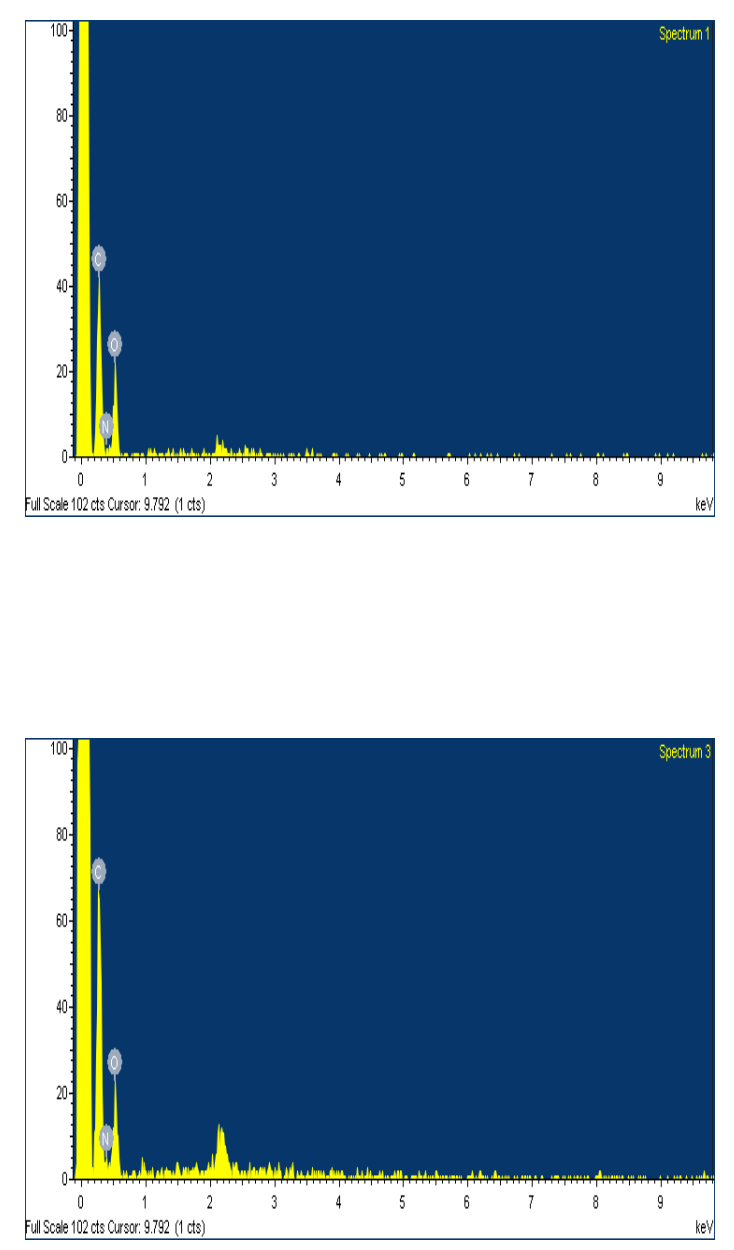

Figure 4. SEM images of chitin before (a) after adsorption (b) 
3.2. Optimization of process conditions via response surface methodology (RSM)

In classical optimization techniques, it is very difficult to determine the real values of process variables. In the present study, RSM was employed in order to obtain maximum RBG 6B dye removal efficiency and to determine the optimal values of the process variables such as the solution $\mathrm{pH}$, initial dye concentration and adsorbent

Table 2. Experimental design and results of the central composite design

\begin{tabular}{|c|c|c|c|c|c|c|}
\hline \multirow{2}{*}{ Runs } & \multirow{2}{*}{$A$} & \multirow{2}{*}{ B } & \multirow{2}{*}{ C } & \multicolumn{2}{|c|}{ \% Removal of RBG 6B } & \multirow{2}{*}{$\begin{array}{c}\text { Experimental } q_{e} \\
\left(\mathrm{mg} \mathrm{g}^{-1}\right)\end{array}$} \\
\hline & & & & Observed & Predicted & \\
\hline 1 & 5.50 & 137.50 & 6.02 & 67.20 & 68.77 & 15.3 \\
\hline 2 & 5.50 & 137.50 & 0.98 & 17.40 & 16.22 & 24.4 \\
\hline 3 & 8.00 & 200.00 & 2.00 & 13.50 & 15.94 & 13.5 \\
\hline 4 & 5.50 & 242.61 & 3.50 & 46.80 & 43.95 & 32.4 \\
\hline 5 & 3.00 & 75.00 & 2.00 & 59.70 & 56.09 & 22.4 \\
\hline 6 & 8.00 & 75.00 & 2.00 & 36.40 & 38.33 & 13.7 \\
\hline 7 & 5.50 & 137.50 & 3.50 & 47.70 & 41.01 & 18.7 \\
\hline 8 & 3.00 & 200.00 & 2.00 & 38.00 & 39.00 & 38.0 \\
\hline 9 & 5.50 & 137.50 & 3.50 & 49.30 & 47.42 & 19.4 \\
\hline 10 & 8.00 & 75.00 & 5.00 & 70.40 & 69.12 & 10.6 \\
\hline 11 & 5.50 & 137.50 & 3.50 & 47.50 & 47.42 & 18.7 \\
\hline 12 & 1.30 & 137.50 & 3.50 & 68.10 & 72.44 & 26.8 \\
\hline 13 & 3.00 & 200.00 & 5.00 & 72.90 & 70.70 & 29.2 \\
\hline 14 & 8.00 & 200.00 & 5.00 & 45.90 & 49.23 & 18.4 \\
\hline 15 & 5.50 & 32.39 & 3.50 & 71.80 & 75.04 & 6.6 \\
\hline 16 & 9.70 & 137.50 & 3.50 & 43.40 & 39.45 & 17.1 \\
\hline 17 & 5.50 & 137.50 & 3.50 & 48.10 & 47.42 & 18.9 \\
\hline 18 & 5.50 & 137.50 & 3.50 & 45.80 & 47.42 & 18.0 \\
\hline 19 & 3.00 & 75.00 & 5.00 & 88.00 & 85.29 & 13.2 \\
\hline 20 & 5.50 & 137.50 & 3.50 & 46.20 & 47.42 & 18.2 \\
\hline
\end{tabular}

Table 3. Analysis of variance (ANOVA) for the fitted quadratic polynomial model of RBG $6 B$ removal efficiency as a function of individual variables and parameter estimates (significance of regression coefficient)

\begin{tabular}{|c|c|c|c|c|c|}
\hline Source & Sum of squares & DF & Mean Square & F-value & P-value Prob $>F$ \\
\hline Model & 6276.86 & 9 & 697.43 & 61.31 & $<0.0001$ \\
\hline$A-\mathrm{pH}$ & 1313.63 & 1 & 1313.63 & 115.48 & $<0.0001$ \\
\hline$B$-RBG 6B con. & 1167.02 & 1 & 1167.02 & 102.59 & $<0.0001$ \\
\hline C-Chitin dosage & 3333.10 & 1 & 3333.10 & 293.02 & $<0.0001$ \\
\hline$A B$ & 14.05 & 1 & 14.05 & 1.23 & 0.2925 \\
\hline$A C$ & 1.28 & 1 & 1.28 & 0.11 & 0.7442 \\
\hline$B C$ & 3.13 & 1 & 3.13 & 0.27 & 0.6116 \\
\hline$A^{2}$ & 130.86 & 1 & 130.86 & 11.50 & 0.0069 \\
\hline$B^{2}$ & 262.57 & 1 & 262.57 & 23.08 & 0.0007 \\
\hline$C^{2}$ & 43.73 & 1 & 43.73 & 3.84 & 0.0783 \\
\hline Residual & 113.75 & 10 & 11.38 & & \\
\hline Lack of Fit & 105.56 & 5 & 21.11 & 12.88 & 0.0070 \\
\hline Pure Error & 8.19 & 5 & 1.64 & & \\
\hline Cor Total & 6390.61 & 19 & & & \\
\hline
\end{tabular}

$R^{2}: 0.9822 ;$ Adj $R^{2}: 0.9662 ;$ Pred $R^{2}: 0.8706 ;$ Adeq Precision: 29.078

The model equation represented the removal efficiency as functions of solution $\mathrm{pH}(A)$, initial RBG $6 \mathrm{~B}$ concentration $(B)$, and chitin dosage $(C)$ could be written as:

Removal of RBG $6 \mathrm{~B}=+47.42-9.81 A-9.24 B+15.62 C-1.32 A B+0.40 A C+0.63 B C+3.01 A^{2}+4.27 B^{2}-1.74 C^{2}$ 
The equation maintained above defines the effect of independent variables on the adsorption of RBG 6B on the chitin and it could be predicted the percentage of dye removal. The maximum removal efficiency of dye was $88 \%$. The solution $\mathrm{pH}(A)$ was between 1.3 and 9.7. The initial dye concentration $(B)$ was between 32.4 and $242.6 \mathrm{mg} \mathrm{L}^{-1}$, and the chitin dosage $(C)$ was varied between 0.98 and $6.02 \mathrm{~g} \mathrm{~L}^{-1}$.

It is required to implement ANOVA analysis to determine that the second-order polynomial model is important or not (Zhang et al., 2016). The fit of the model was evaluated by coefficient of determination $\left(R^{2}\right)$ and analysis of variance (ANOVA). Table 3 shows the results for analysis of variance (ANOVA). The significant criterion is $P<0.05$. As seen in Table 3, the second order polynomial model was statistically significant $(P<0.0001)$. Based on the analysis of the model equation coefficient significance, solution $\mathrm{pH}$, initial RBG 6B concentration and chitin dosage have a significant effect $(P<0.0001)$ on the adsorption of RBG 6B from aqueous solution (with a $95 \%$ confidence limit) and the quadratic terms of $\mathrm{pH}$ and initial RBG $6 \mathrm{~B}$ concentration are significant. However, the interaction terms $(A B, A C$ and $B C)$ and quadratic term of adsorbent dosage are not significant. In addition, based on the coefficients of $R^{2}=0.9822$ and adjusted $R^{2}=0.9662$, the high quantity of fitness could be revealed, and only $1.78 \%$ of total variation was not explained by the model. The high adjusted $R^{2}$ values indicate a good correlation and relationship between the experimental results and results obtained model. The Model F-value of 61.31 refers that the model is important. In addition, the coefficient of variation is $10 \%$ $(\mathrm{CV}=6.59 \%)$.
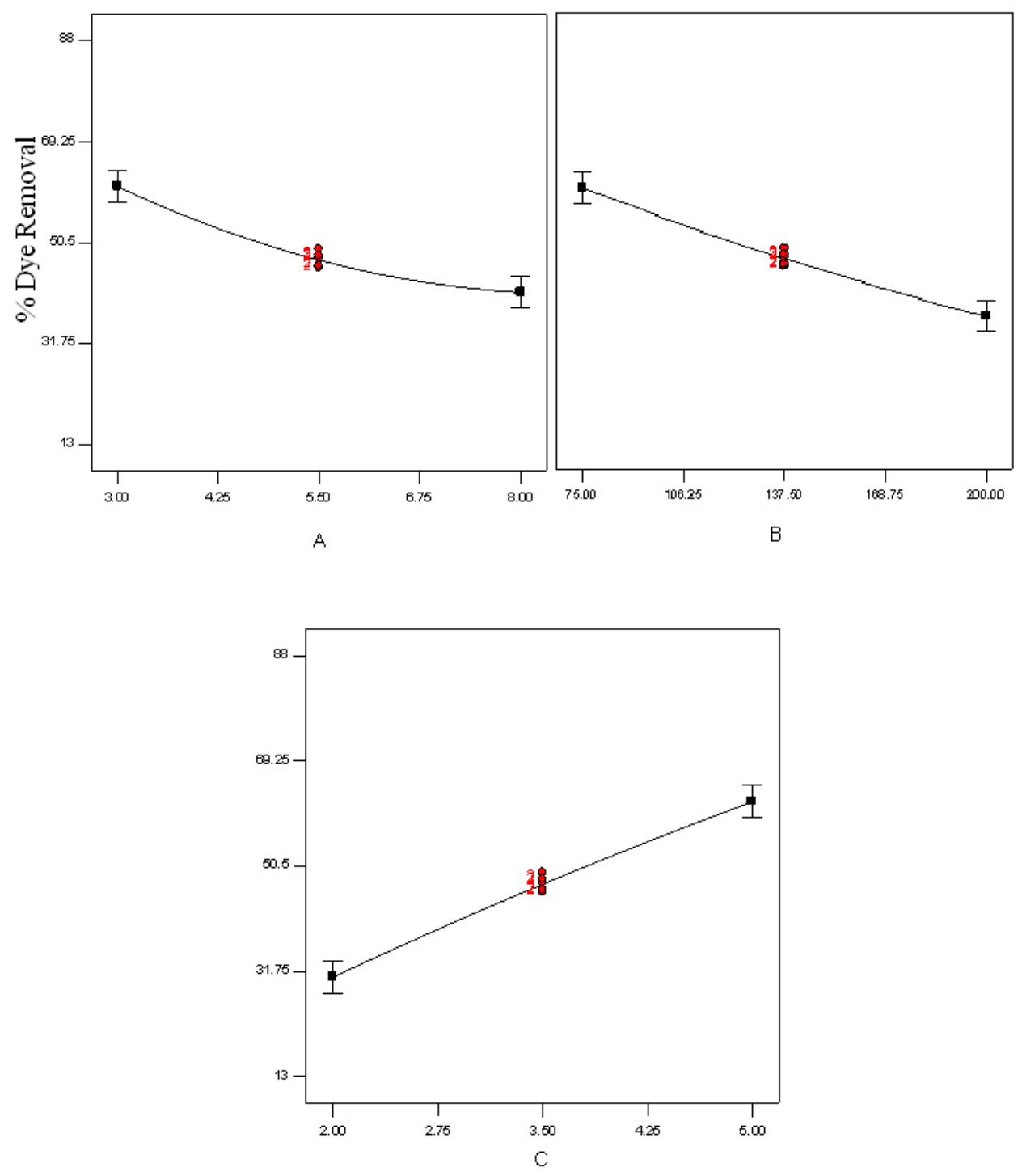

Figure 5. Overall effects of solution $\mathrm{pH}(A)$, initial RBG 6B concentration $(B)$ and chitin dosage $(C)$ on RBG 6B removal using chitin

Fig. 5 indicates the overall effects of solution $\mathrm{pH}$, initial RBG $6 \mathrm{~B}$ concentration and chitin dosage. The increase in the solution $\mathrm{pH}$ causes to a decrease on dye removal. The effect of initial dye concentration on dye removal specifies that increasing of dye concentration causes to a linear diminish on the removal efficiency. Furthermore, increasing the chitin dosage causes to a linear rise of the removal efficiency in the model. Fig. 6 presents the graph 
of the actual data of removal efficiency against envisaged values using the model. Based on Fig. 6, the proper fitness between actual and predicted data could be clarified.

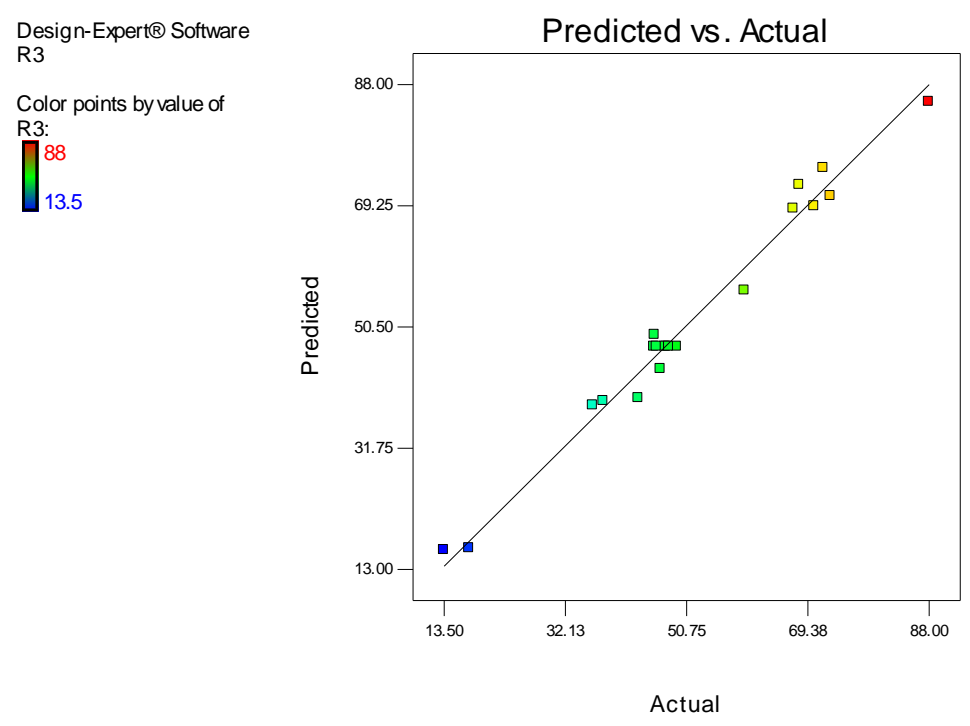

Figure 6. The actual data versus predicted data for removal of RBG 6B

Maximum removal efficiency with chitin and suitable optimum experimental conditions of independent variables are determined using the desirability function of Design Expert Software (Fig. 7). The determined optimum conditions are the solution $\mathrm{pH}$ of 3.0, the initial RBG 6B concentration of $75.0 \mathrm{mg} \mathrm{L}^{-1}$ and the adsorbent dosage of 5 $\mathrm{g} \mathrm{L}^{-1}$. Under these conditions the removal efficiency is 86.42 $\%$.

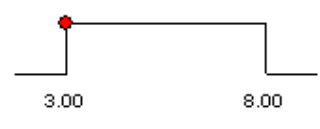

$\mathrm{pH}=3.00$

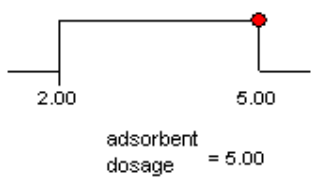

Desirability $=0.979$

Figure 7. Desirability ramp for numerical optimization of three independent variables, solution pH initial RBG 6B concentration and chitin dosage

\subsubsection{Effect of solution $\mathrm{pH}$ on the response}

The solution $\mathrm{pH}$ is an important factor affecting adsorption, because it can change surface charge of the adsorbent, the degree of ionization and the speciation of adsorbate species (Iqbal et al., 2016). The $\mathrm{pH}$ values between 1.30 and 9.70 were selected according to central composite design, and it was revealed that the dye removal efficiency diminished by increasing the solution $\mathrm{pH}$. The removal efficiencies of RBG $6 B$ at $\mathrm{pH} 1.30,5.50$ and 9.70 (dye concentration:137.50 $\mathrm{mg} \mathrm{L}^{-1}$ and adsorbent dosage:3.50 g $\mathrm{L}^{-1}$ ) were 68.1, 47.4 (average) and $43.4 \%$, respectively. Similarly, the adsorption capacity of chitin at $\mathrm{pH} 1.30,5.50$ and 9.70 were 26.8, 20.1 (average) and $17.1 \mathrm{mg} \mathrm{g}^{-1}$, respectively. The point of zero charge $\left(\mathrm{pH}_{p z c}\right)$ of chitin is approximately 5.4-7.2 (Gonzalez-Davila and Millero, 1990; Khedr et al., 2012; Szymczyk et al., 2016). In the adsorption of RBG 6B dye on chitin, at $\mathrm{pH}$ values below the point of zero charge $\left(p H_{p z c}\right)(<\sim 6.0)$, the chitin will have a net positive charge due to protonation of nitrogen-containing functional groups such as amines. The $p K a$ value of the sulfonyl groups ( $\mathrm{RSO}_{2}-\mathrm{OH}$ ) in the structure of RBG $6 \mathrm{~B}$ dye is $<1$ (Rice, 2014). It is expected that positively charged functional groups on the adsorbent surface will favor the adsorption of negatively charged dye anions due to electrostatic attraction. At acidic $\mathrm{pH}$ values, the electrostatic attractions enhanced between dye anions and adsorption sites of chitin and dye removal increased. However, the positively charged sites of chitin diminish with the increment of $\mathrm{pH}$, and the surface of chitin becomes negatively charged. This condition does not helpful for the adsorption of anionic dye and cause electrostatic repulsion. Hydroxyl ions are in competition with dye ions at high $\mathrm{pH}$, and adsorption of the dye from aqueous solution decrease. The similar results were observed for removal of anionic dyes onto several adsorbents (Banerjee and Chattopadhyaya, 2017).

\subsubsection{Effect of dye concentration on the response}

Initial dye concentrations ensure a significant driving force for transfer of dye molecules between the dye solution and chitin (Pavlović et al., 2014). The initial dye concentration $(B)$ was between 32.4 and $242.6 \mathrm{mg} \mathrm{L}^{-1}$ according to central composite design. The dye removal efficiency significantly declined from $71.8 \%$ to $46.8 \%$ when the initial concentration rose from 32.4 to $242.6 \mathrm{mg} \mathrm{L}^{-1}$ at chitin 
dosage of $3.5 \mathrm{~g} \mathrm{~L}^{-1}$ and $\mathrm{pH}$ 5.5. At low dye concentrations, as the ratio of active sites of chitin surface to the total RBG $6 B$ molecules in the solution is high, most of RBG $6 B$ molecules may interact with active sites of chitin surface and be adsorbed from the solution (Kakavandi et al., 2016). At high initial RBG 6B concentration, the ratio of surface active sites of chitin to the total RBG $6 B$ molecules in the

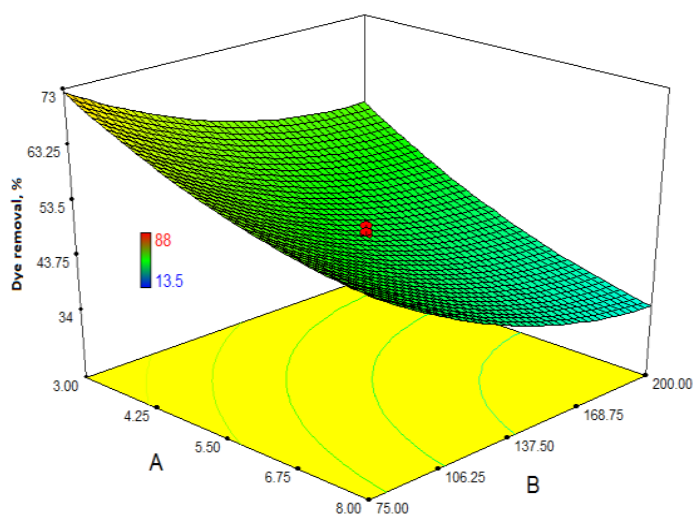

(a)

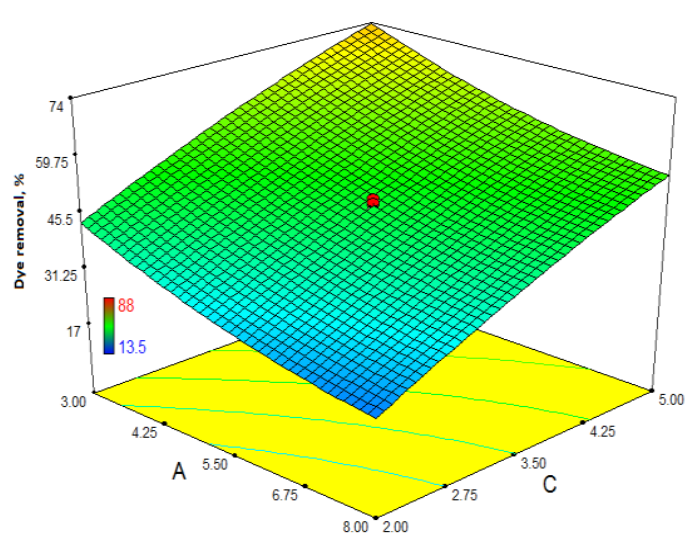

(c)

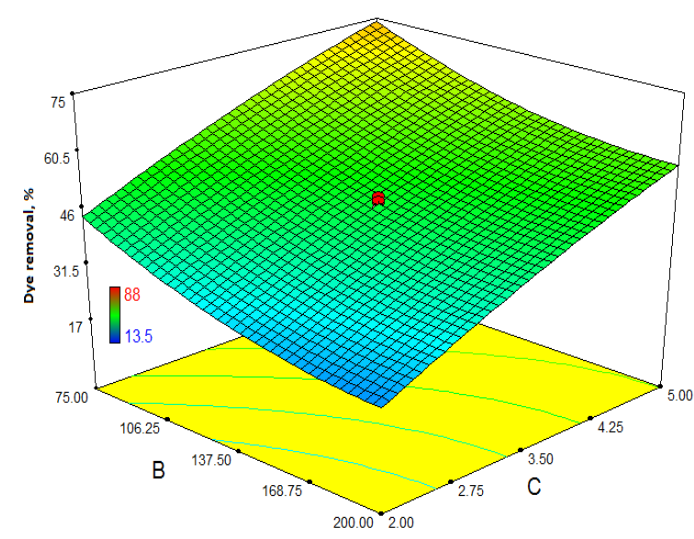

(e) solution is low, thus removal efficiencies fall. At same conditions, the adsorption capacity of chitin at initial dye concentration of $32.4,137.5$ and $242.6 \mathrm{mg} \mathrm{L}^{-1}$ were 6.6 , 20.1 (average) and $32.4 \mathrm{mg} \mathrm{g}^{-1}$, respectively. At high initial dye concentration, with increasing of driving force, adsorption capacity increased.

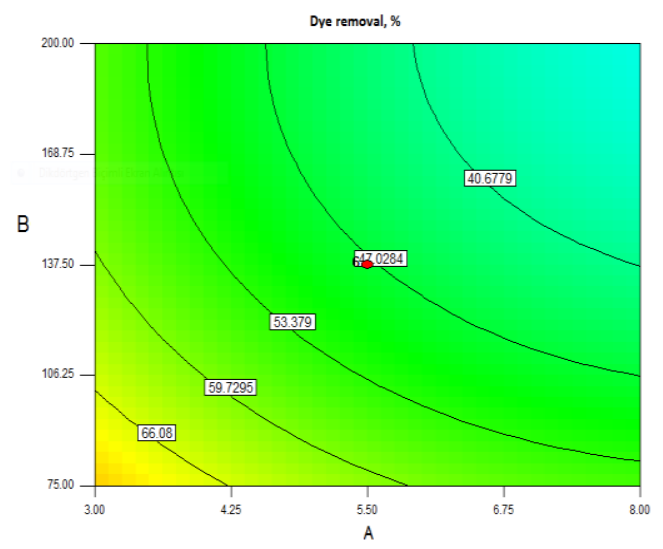

(b)

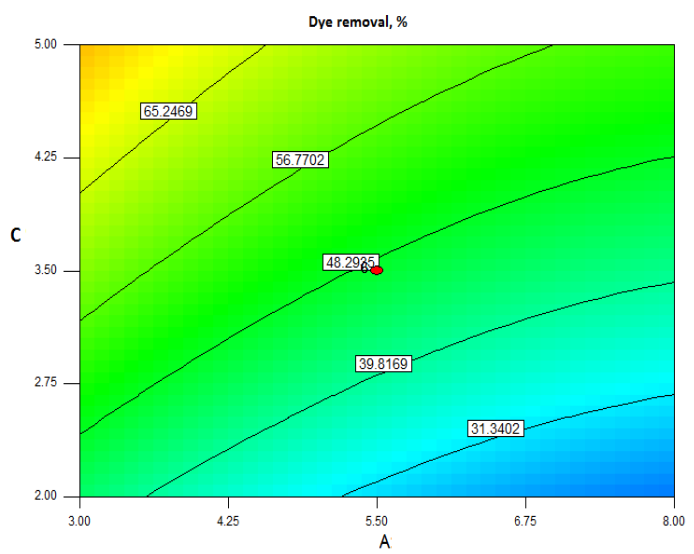

(d)

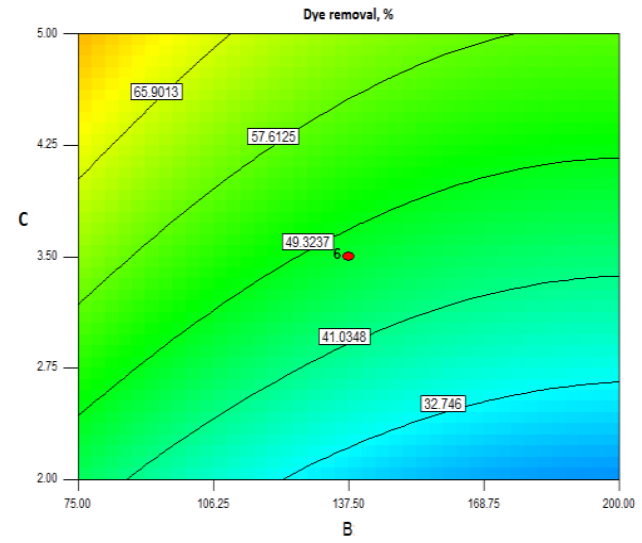

(f)

Figure 8. The three-dimensional response surface and the two dimensional contour curves for removal of RBG 6B 


\subsubsection{Effect of adsorbent dosage on the response}

The removal percentages of contaminants via adsorption are enhanced quite by the amounts of adsorbent. With increasing of the chitin from 0.98 to $6.02 \mathrm{~g} \mathrm{~L}^{-1}$, removal efficiency increased from 17.4 to $67.2 \%$ at the initial dye concentration of $137.5 \mathrm{mg} \mathrm{L}^{-1}$ and solution $\mathrm{pH}$ of 5.5. This characteristic can be dedicated to the fact that high chitin dosage leads to increase the surface area and the number of active sites of chitin (Kakavandi et al., 2016). But the adsorption capacity of chitin was decreased from 24.4 to $15.3 \mathrm{mg} \mathrm{g}^{-1}$ with the increasing in chitin dosage. This case can be explained by enhancing the number of active sites with increasing chitin dosage and remaining of unsaturated sites (Pavlović et al., 2014).

Response surface curves are drawn with a statistically appropriate model to find optimal conditions necessary for the maximum dye removal and to understand the interaction of process variables. The 3D and the 2D curves are generally the graphical representation of the regression equation (Eqs. (3)). Each curve indicates endless combinations of other two test variables when one test variable maintains at zero level. The surface covered in the smallest ellipse in the contour curve specifies the highest predicted value of response (Elibol, 2004). The response surface graphs are given in Fig. 8 (a-f). The highest removal $(88 \%)$ was obtained at solution $\mathrm{pH}$ of 3.0 , initial dye concentration of $75 \mathrm{mg} \mathrm{L}^{-1}$ and chitin dosage of $5.0 \mathrm{~g} \mathrm{~L}^{-1}$. Also, the maximum dye amount adsorbed at equilibrium (38.0 $\mathrm{mg} \mathrm{g}^{-1}$ ) was determined at solution $\mathrm{pH}$ of 3.0, initial dye concentration of $200 \mathrm{mg} \mathrm{L}^{-1}$ and chitin dosage of $2.0 \mathrm{~g}$ $\mathrm{L}^{-1}$. The effects of solution $\mathrm{pH}$ and dye concentration are shown in Fig. 8 (a-b). As can be seen from Fig. 8 (a-b), the maximum removal of dye was achieved at the lowest solution $\mathrm{pH}(1.3)$ and dye concentration (32.4 $\left.\mathrm{mg} \mathrm{L}^{-1}\right)$. The effects of solution $\mathrm{pH}$ and chitin dosage are shown in Fig. 8 (c-d). Maximum removal of dye was obtained at the lowest solution $\mathrm{pH}(1.3)$ and the highest chitin dosage $\left(6.02 \mathrm{~g} \mathrm{~L}^{-1}\right)$. Similarly, the effects of dye concentration and chitin dosage are shown in Fig. 8 (e-f). Maximum removal was observed at the lowest dye $\left(32.4 \mathrm{mg} \mathrm{L}^{-1}\right)$ and the highest chitin dosage $\left(6.02 \mathrm{~g} \mathrm{~L}^{-1}\right)$.

The comparison of adsorption capacity of chitin used in this study with those obtained in the literature was given in Table 4. Comparing with other adsorbents, chitin (38.0 $\mathrm{mg} \mathrm{g}^{-1}$ at solution $\mathrm{pH}$ of 3.0, initial dye concentration of $200 \mathrm{mg} \mathrm{L}^{-1}$ and chitin dosage of $2.0 \mathrm{~g} \mathrm{~L}^{-1}$ ) used in this study had a relatively high adsorption uptake.

Table 4. Comparison of the maximum adsorption capacities of different dyes on various adsorbents

\begin{tabular}{|c|c|c|c|}
\hline Adsorbent & Adsorbate & $\mathrm{q}_{\mathrm{m}, \mathrm{mg} \mathrm{g}^{-1}}$ & References \\
\hline Chitin nanowhiskers & Crystal violet & 39.56 & Gopi et al., 2016 \\
\hline Ultrasonic surface modified chitin & Methylene Blue & 26.69 & Dotto et al., 2015 \\
\hline $\begin{array}{c}\text { CuS nanoparticle loaded on activated } \\
\text { carbon }\end{array}$ & $\begin{array}{l}\text { Bromophenol blue } \\
\text { Methylene blue }\end{array}$ & $\begin{array}{l}106.4 \\
208.3\end{array}$ & Mazaheri et. al., 2016 \\
\hline Microwave assisted sawdust & Methylene blue & 58.14 & Suganya et al., 2017 \\
\hline ZnO/chitosan coating layer & Methyl orange & 42.8 & Kamal et al., 2015 \\
\hline Sodium bentonite & $\begin{array}{l}\text { Bezathren-Blue } \\
\text { Bezathren-Green } \\
\text { Bezathren-Red }\end{array}$ & $\begin{array}{l}35.08 \\
32.88 \\
48.52\end{array}$ & Belbachir et al., 2017 \\
\hline Graphene oxide & $\begin{array}{l}\text { Direct Red } 23 \\
\text { Acid Orange } 8\end{array}$ & $\begin{array}{l}15.3 \\
29.0\end{array}$ & Konicki et al., 2017 \\
\hline Chitin & Remazol Brillant Green 6B & 38.0 & This study \\
\hline
\end{tabular}

\subsection{Adsorption isotherms}

The equilibrium parameters provide basic requirements for the design of adsorption systems such as the relationship between the substance adsorbed and the adsorbent and information on the capacity of the adsorbent (Tanyol et al., 2015; Tanyol, 2017). Equilibrium adsorption isotherm models often used by researcher are Langmuir and Freundlich isotherms (Dursun et al., 2013). The Langmuir model is used to describe monolayer adsorption of contaminants onto a surface (Haldorai et al., 2015). Freundlich model is used to describe adsorption on a heterogeneous surface, suggesting that binding sites are not equivalent and/or independent. The Langmuir and Freundlich isotherms are given by (Eq.4) and (Eq. 5), respectively (Langmuir, 1918; Freundlich, 1906).

$$
\begin{aligned}
& \frac{\mathrm{C}_{e}}{\mathrm{q}_{e}}=\frac{1}{\mathrm{Kq}_{\max }}+\frac{\mathrm{C}_{\mathrm{e}}}{\mathrm{q}_{\max }} \\
& \ln \mathrm{q}_{\mathrm{e}}=\ln \mathrm{K}_{\mathrm{f}}+\frac{1}{\mathrm{n}} \ln \mathrm{C}_{\mathrm{e}}
\end{aligned}
$$

Where $q_{\max }$ is the maximum adsorption capacity $\left(\mathrm{mg} \mathrm{g}^{-1}\right) . K$ $\left(\mathrm{L} \mathrm{mg}^{-1}\right)$ is the equilibrium constant related to affinity of binding sites or bonding energy of adsorption. $K_{f}$ and $1 / n$ are parameters indicating the capacity and intensity of adsorption, respectively. These models were applied to investigate the experimental equilibrium data obtained from the adsorption at the concentration range of 32.39$242.61 \mathrm{mg} \mathrm{L}^{-1}$, chitin dosage of $3.5 \mathrm{~g} \mathrm{~L}^{-1}$ and $\mathrm{pH}$ 5.5. The Freundlich and Langmuir model constants were analyzed by plotting In $q_{e}$ versus $\ln C_{e}$ and $C_{e} / q_{e}$ versus $C_{e}$, 
respectively. The isotherm constants and correlation coefficients are listed in Table 5.

Table 5. Equilibrium isotherm constants of adsorption of RBG 6B by chitin

\begin{tabular}{cccccc}
\hline & Langmuir model & \multicolumn{3}{c}{ Freundlich model } \\
\hline$q_{\max }\left(\mathrm{mg} \mathrm{g}^{-1}\right)$ & $K\left(\mathrm{~L} \mathrm{mg}^{-1}\right)$ & $R^{2}$ & $K_{F}\left(\left(\mathrm{mg} \mathrm{g}^{-1}\right)\left(\mathrm{mg} \mathrm{L}^{-1}\right)^{\mathrm{n}}\right)$ & $1 / n$ & $R^{2}$ \\
\hline 38.00 & 0.023178 & 0.9784 & 2.29 & 0.49 & 0.9998 \\
\hline
\end{tabular}

The maximum adsorption capacity of RBG 6B $\left(q_{\max }\right)$ on chitin and value of $K$ were $34.48 \mathrm{mg} \mathrm{g}^{-1}$ and 0.023178 $\mathrm{L} \mathrm{mg}^{-1}$ according to Langmuir isotherm model, respectively. The correlation coefficient of Freundlich model $\left(R^{2}>0.99\right)$ is higher than the Langmuir isotherm $\left(R^{2}>0.97\right)$. It was demonstrated that the Freundlich isotherm exhibited best fit with the adsorption data in comparison with the Langmuir isotherm under the concentration range studied. Value of $K_{f}$ was found to be $2.29 \mathrm{mg} \mathrm{g}^{-1}$. When Freundlich constant $(1 / n)$ is $0.1<1 / n \leq 0.5$, adsorption is wonderful; $0.5<1 / n \leq 1$, it is easy to adsorb; $1 / n>1$, there is difficult to adsorb (Tang et al., 2012). As seen in Table 5 , the $1 / \mathrm{n}$ was 0.49 . This is an indicator that adsorption of RBG $6 B$ on chitin could be wonderful. Furthermore, these results assumed heterogeneity of chitin surfaces.

\subsection{Adsorption kinetics}

Kinetic models are used to examine the rate of the adsorption process and potential rate-controlling step, i.e., mass transfer or chemical reaction (Dursun and Kalayci, 2005). Pseudo-first order and pseudo-second order models can be used to test the adsorption. The pseudo-first-order and pseudo-second-order equations are represented in Eqs. (6) and (7), respectively.

$$
\begin{aligned}
& \log \left(\mathrm{q}_{\mathrm{e}}-\mathrm{q}_{\mathrm{t}}\right)=\log \mathrm{q}_{\mathrm{e}}-\left(\frac{\mathrm{k}_{1}}{2.303}\right) \mathrm{t} \\
& \frac{\mathrm{t}}{\mathrm{q}_{\mathrm{t}}}=\frac{1}{\mathrm{k}_{2} \mathrm{q}_{\mathrm{e}}^{2}}+\frac{\mathrm{t}}{\mathrm{q}_{\mathrm{e}}}
\end{aligned}
$$

Where $k_{1}$ and $k_{2}$ are the pseudo-first and pseudo-secondorder rate constants, respectively (Lagergren, 1898; Ho and McKay, 1999). The experimental results were fitted to these kinetic models. Experimental parameters such as solution $\mathrm{pH}$, the chitin dosage and contact time were 5.5, $3.5 \mathrm{~g} \mathrm{~L}^{-1}$ and $360 \mathrm{~min}$, respectively. Constants of pseudofirst order and second order-kinetics models were determined by linearised plotting $\log \left(q_{e}-q_{t}\right)$ versus $t$ and $t / q_{t}$ versus $t$, respectively. The values of the kinetic parameters and correlation coefficients for different concentrations are shown in Table 6.

Table 6. A comparison of the first and second-order rate constants and the calculated and experimental $q_{e}$ values obtained

\begin{tabular}{|c|c|c|c|c|c|c|c|}
\hline \multirow[b]{2}{*}{$C_{o}\left(\mathrm{mg} \mathrm{L}^{-1}\right)$} & \multirow{2}{*}{$\begin{array}{c}q_{e, \exp }\left(\mathrm{mg} \mathrm{g}^{-}\right. \\
\left.{ }^{1}\right)\end{array}$} & \multicolumn{3}{|c|}{ The pseudo first-order kinetic } & \multicolumn{3}{|c|}{ The pseudo-second-order kinetic } \\
\hline & & $k_{1}\left(\min ^{-1}\right)$ & $q_{e, c a l}\left(\mathrm{mg} \mathrm{g}^{-1}\right)$ & $R^{2}$ & $k_{2}\left(\mathrm{~g} \mathrm{mg}^{-1} \mathrm{~min}^{-1}\right)$ & $q_{e, c a l}\left(\mathrm{mg} \mathrm{g}^{-1}\right)$ & $R^{2}$ \\
\hline 32.39 & 6.6 & 0.0089817 & 5.71 & 0.97 & 0.001902 & 8.00 & 0.99 \\
\hline 137.5 & 20.1 & 0.0080605 & 16.75 & 0.99 & 0.000455 & 23.20 & 0.99 \\
\hline 242.61 & 32.4 & 0.0078302 & 19.02 & 0.92 & 0.000661 & 29.50 & 0.99 \\
\hline
\end{tabular}
at different initial RBG 6B concentrations

$R^{2}$ values and calculated $q_{e}$ values are commonly used to determine the suitability of the kinetic model. The $R^{2}$ values of pseudo-first-order kinetic model were 0.97, 0.99 and 0.92 for the dye concentrations of $32.4,137.5$ and 242.6 $\mathrm{mg} \mathrm{L}^{-1}$, respectively while these values for pseudo-secondorder kinetic were 0.99 for all the concentrations. For pseudo-second-order kinetic model, the values of correlation coefficient were higher than pseudo-first-order kinetic model. In addition, the calculated $q_{e}$ values agreed more perfectly with the experimental $q_{e}$ values. These results suggest that the adsorption process is more fitted by the pseudo second-order model. The pseudo-secondorder kinetic model is also based on the sorption capacity of the solid phase and on the assumption that the sorption process involves chemisorption mechanism. The similar results were also obtained by other researchers investigating dye removal by various adsorbents (Ghaedi et al., 2016).

\section{Conclusion}

In this study, it was demonstrated that the chitin can be successfully utilized in RBG 6B removal from aqueous solution and sorption studies by applying of response surface methodology can offer less expensive experiments for optimizing operation conditions in RBG 6B removal. It was found that the individual variables as solution $\mathrm{pH}$, initial RBG 6B concentration and chitin dosage played an important role in the adsorption of RBG $6 B$ on chitin. The data obtained equilibrium and kinetic studies demonstrated that the adsorption of RBG $6 \mathrm{~B}$ on chitin fitted well the Freundlich isotherm and followed the pseudo-second-order model. This study is also extendable for the adsorption of other contaminants from effluents.

\section{References}

Agarwal S., Tyagi I., Gupta V.K., Bagheri A.R., Ghaedi M., Asfaram A., Hajati S. and Bazrafshan A.A. (2016), Rapid adsorption of ternary dye pollutants onto copper (I) oxide nanoparticle 
loaded on activated carbon: Experimental optimization via response surface methodology, J. Env. Chem. Eng., 4, 1769-1779.

Akkaya G., Uzun I. and Güzel F. (2007), Kinetics of the adsorption of reactive dyes by chitin, Dye Pigments, 73, 168-177.

Banerjee S. and Chattopadhyaya M.C. (2017), Adsorption characteristics for the removal of a toxic dye, tartrazine from aqueous solutions by a low cost agricultural by-product, Arab. J. Chem., 10, S1629-S1638.

Belbachir I. and Makhoukhi B. (2017), Adsorption of Bezathren dyes onto sodic bentonite from aqueous solutions, J. Taiwan Inst. Chem. Eng., 75, 105-111.

Cárdenas G., Cabrera G., Taboada E. and Miranda S.P. (2004), Chitin characterization by SEM, FTIR, XRD and $13 \mathrm{c}$ cross polarization/mass angle spinning NMR, J. Applied Polymer. Sci., 93, 1876-1885.

Dasgupta J., Singh A., Kumar S., Sikder J., Chakraborty S., Curcio S. and Arafat H.A. (2016), Poly (sodium-4-styrenesulfonate) assisted ultrafiltration for methylene blue dye removal from simulated wastewater: optimization using response surface methodology, J. Environ. Chem. Eng., 4, 2008-2022.

Dhananasekaran S., Palanivel R. and Pappu S. (2016), Adsorption of methylene blue, bromophenol blue, and coomassie brillant blue by $\alpha$-chitin, J. Advan Res., 7, 113-124

Dolphen R. and Thiravetyan T. (2011), Adsorption of melanoidins by chitin nanofibers, Chem. Eng. J., 166, 890-895.

Dotto G.L., Santos J.M.N., Rodrigues I.L., Rosa R., Pavan F.A. and Lim E.C. (2015), Adsorption of methylene blue by ultrasonic surface modified chitin, J. Colloid Interface Sci., 446, 133-140.

Dotto G.L., Vieira M.L.G. and Pinto L.A.A. (2012), Kinetics and mechanism of tartrazine adsorption onto chitin and chitosan, Ind. Eng. Chem. Res., 51, 6862-6868.

Dursun A.Y. and Kalayci Ç.S. (2005), Equilibrium kinetic and thermodynamic studies on the adsorption of phenol onto chitin, J. Hazard. Mater., B123, 151-157.

Dursun A.Y., Tepe O. and Dursun G. (2013), Use of carbonised beet pulp carbon for removal of remazol turquoise blue-G 133 from aqueous solution, Environ. Sci. Pol. Res., 20(1), 431-442.

Elibol M. (2004), Optimization of medium composition for actinorhodin production by Streptomyces coelicolor A3 (2) with response surface methodology, Process Biochem., 39, 1057-1062.

Erdogan S. and Kaya M. (2016), High similarity in physicochemical properties of chitin and chitosan from nymphs and adults of a grasshopper, Int. J. Biol. Macromol., 89, 118-126.

Freundlich H.M.F. (1906), Over the adsorption in solution, J. Phys. Chem., 57A, 385-470.

Ghaedi M., Zare Khafri H., Asfaram A. and Goudarzi A. (2016), Response surface methodology approach for optimization of adsorption of janus green $b$ from aqueous solution onto $\mathrm{Zno} / \mathrm{Zn}(\mathrm{OH})_{2}$-NP-AC: kinetic and isotherm study, Spectrochim. Acta A, 152, 233-240.

Gonzalez-Davila M. and Millero F.J. (1990), The adsorption of copper to chitin in seawater, Geochim. Cosmochim. Acta, 54, 761-768.

Gopi S., Pius A. and Thomas S. (2016), Enhanced adsorption of crystal violet by synthesized and characterized chitin nano whiskers from shrimp shell, J. Water Process Eng., 14, 1-8.

Haldorai Y., Rengaraj A., Ryu T., Shin J., Huh Y.S. and Han Y.-K. (2015), Response surface methodology for the optimization of lanthanum removal from an aqueous solution using a $\mathrm{Fe}_{3} \mathrm{O}_{4} /$ Chitosan Nanocomposite, Mater. Sci. Eng. B, 195, 20-29.

Ho Y.S. and McKay G. (1999), Pseudo-second order model for sorption processes, Process Biochem., 34, 451-465.

lqbal M., Iqbal N., Bhatti I.A., Ahmad N. and Zahid M. (2016), Response surface methodology application in optimization of cadmium adsorption by shoe waste: a good option of waste mitigation by waste, Ecol. Eng., 88, 265-275.

Kakavandi B., Jahangirirad M., Rafiee M., Esfahani A.R. and Babaei A.E. (2016), Development of response surface methodology for optimization of phenol and p-chlorophenol adsorption on magnetic recoverable carbon, Microporous Mesoporous Mater., 231, 192-206.

Kamal T., UI-Islam M., Khan S.B. and Asiri A.M. (2015), Adsorption and photocatalyst assisted dye removal and bactericidal performance of $\mathrm{ZnO} /$ Chitosan coating layer, Int. J. Biol. Macromol., 81, 584-590.

Kaya M., Mulerčikas P., Sargin I., Kazlauskaitè S., Baublys V., Akyuz B., Bulut E. and Tubelytè V. (2016), Three-dimensional chitin rings from body segments of a pet diplopod species: characterization and protein interaction studies, Mater. Sci. Eng. C, 68, 716-722.

Khedr S.A., Shouman M.A. and Attia A.A. (2012), Adsorption studies on the removal of cationic dye from shrimp shell using chitin, Biointerface Res. Appl. Chem., 3(1), 507-519.

Konicki W., Aleksandrzak M., Moszynski D. and Mijowska E. (2017), Adsorption of anionic azo-dyes from aqueous solutions onto graphene oxide: equilibrium, kinetic and thermodynamic studies, J. Colloid Interface Sci., 496, 188-200.

Labidi A., Salaberria A.M., Fernandes S.C.M., Labidi J. and Abderrabba M. (2016), Adsorption of copper on chitin-based materials: kinetic and thermodynamic studies, J. Taiwan Instit. Chem. Eng., 65, 140-148.

Lagergren S. (1898), Zur theorie der sogenannten adsorption geloster stoffe, Kungliga svenska vetenkapsakademiens, Handlingar 24, 1-39.

Langmuir I. (1918), The adsorption of gases on plane surfaces of glass, mica and platinum, J. Am. Chem. Soc., 40(9), 1361-1403.

Matthews R.D., Bottomley L.A. and Pavlostathis S.G. (2009), Palladium-catalyzed hydrogen reduction and decolorization of reactive phthalocyanine dyes, Desalination, 248, 816-825.

Mazaheri H., Ghaedi M., Asfaram A. and Hajati S. (2016), Performance of CuS nanoparticle loaded on activated carbon in the adsorption of methylene blue and bromophenol blue dyes in binary aqueous solutions: using ultrasound power and optimization by central composite design, J. Mol. Liq., 219, 667-676.

Pavlović M.D., Buntić A.V., Mihajlovski K.R., Šiler-Marinković S.S., Antonović D.G., Radovanović Ž. and Dimitrijević-Branković S.I. (2014), Rapid cationic dye adsorption on polyphenolextracted coffee grounds-a response surface methodology approach, J. Taiwan Instit. Chem. Eng., 45, 1691-1699.

Ravikumar K., Pakshirajan K., Swaminathan T. and Balu K. (2005), Optimization of batch process parameters using response surface methodology for dye removal by a novel adsorbent, Chem. Eng. J., 105, 131-138. 
Rice J.E. (2014), Organic chemistry concepts and applications for medicinal chemistry. Chapter 4, Acids and bases, pp. 75, Elsevier, San Diego, USA.

Rumengan I.F.M., Suryanto E., Modaso R., Wullur S., Tallei T.E. and Limbong D. (2014), Structural characteristics of chitin and chitosan isolated from the biomass of cultivated rotifer, Brachionus rotundiformis. Int. J. Fish. Aqua. Sci., 3(1), 12-18.

Shankara S., Reddya J.P., Rhima J.-W. and Kim H.Y. (2015), Preparation, characterization, and antimicrobial activity of chitin nanofibrils reinforced carrageenan nanocomposite films, Carbohydr. Polym., 117, 468-475.

Silva M.C., Corrêa A.D., Amorim M.T.S.P., Parpot P., Torres J.A. and Chagas P.M.B. (2012), Decolorization of the phthalocyanine dye reactive blue 21 by turnip peroxidase and assessment of its oxidation products, J. Molecular Catal. B Enzym., 77, 9-14.

Sohrabi M.R., Moghri M., Masoumi H.R.F., Amiri S., and Moosavi N. (2016), Optimization of reactive blue 21 removal by nanoscale zero-valent iron using response surface methodology, Arabian J. Chem., 9, 518-525.

Subramaniam R. and Ponnusamy S.K. (2015), Novel adsorbent from agricultural waste (cashew nut shell) for methylene blue dye removal: optimization by response surface methodology, Water Resour. Ind., 11, 64-70.

Suganya S., Senthil Kumar P., Saravanan A., Sundar Rajan P. and Ravikumar C. (2017), Computation of adsorption parameters for the removal of dye from wastewater by microwave assisted sawdust: theoretical and experimental analysis, Environ. Toxicol. Pharmacol., 50, 45-57.

Szymczyk P., Filipkowska U., Jóźwiak T. and KuczajowskaZadrożna M. (2016), Phosphate removal from aqueous solutıons by chitin and chitosan in flakes, Prog. Chem. Appl. Chitin Der., XXI, 192-202.

Tang H., Zhou W. and Zhang L. (2012), Adsorption isotherms and kinetics studies of malachite green on chitin hydrogels, $J$. Hazard. Mater., 209-210, 218-225.

Tanyol M. (2017), Rapid malachite green removal from aqueous solution by natural zeolite: process optimization by response surface methodology, Desalin. Water Treat., 65, 294-303.

Tanyol M., Yonten V. and Demir V. (2015), Removal of phosphate from aqueous solutions by chemical and thermal-modified bentonite clay, Water Air Soil Pollut., 226, 269.

Tehrani M.S. and Zare-Dorabei R. (2016), Competitive removal of hazardous dyes from aqueous solution by mil-68(al): derivative spectrophotometric method and response surface methodology approach, Spectrochim. Acta A, 160, 8-18.

Waśko A., Bulak P., Polak-Berecka M., Nowak K., Polakowski C. and Bieganowski A. (2016), The first report of the physicochemical structure of chitin isolated from Hermetiaillucens, Int. J. Biol. Macromol., 92, 316-320.

Zhang D.-H., Zhang J.-Y., Che W.-C. and Wang Y. (2016), A new approach to synthesis of benzyl cinnamate: optimization by response surface methodology, Food Chem., 206, 44-49. 